\title{
Myosin X and Cytoskeletal Reorganization
}

\author{
Mitsuo Ikebe*, Osamu Sato, Tsuyoshi Sakai
}

Department of Cellular and Molecular Biology, University of Texas Health Science Center at Tyler, Tyler, TX 75708-3154, USA

*Correspondence to:

Ikebe $\mathrm{M}$,

(iD http://orcid.org/0000-0002-8299-6643

Tel: +1-903-877-7785

Fax: $+1-903-877-7316$

E-mail: Mitsuo.Ikebe@uthct.edu

Received April 11, 2018

Revised May 31, 2018

Accepted June 19, 2018
Myosin $\mathrm{X}$ is one of myosin superfamily members having unique cellular functions on cytoskeletal reorganization. One of the most important cellular functions of myosin $\mathrm{X}$ is to facilitate the formation of membrane protrusions. Since membrane protrusions are important factors for diverse cellular motile processes including cell migration, cell invasion, path-finding of the cells, intercellular communications and so on, it has been thought that myosin X plays an important role in various processes that involve cytoskeletal reorganization including cancer progression and development of neuronal diseases. Recent studies have revealed that the unique cellular function of myosin $\mathrm{X}$ is closely correlated with its unique structural characteristics and motor properties. Moreover, it is found that the molecular and cellular activities of myosin X are controlled by its specific binding partner. Since recent studies have revealed the presence of various specific binding partners of myosin $\mathrm{X}$, it is anticipated that the structural, biochemical and cell biological understanding of the binding partner dependent regulation of myosin $\mathrm{X}$ function can uncover the role of myosin $\mathrm{X}$ in diverse cell biological processes and diseases.

Key Words: Myosin X, Motor proteins, Processive movement, Membrane protrusions, Cytoskeletal structure

\section{INTRODUCTION}

Myosin X was first found in vertebrates and subsequently in filasterea (Berg \& Cheney, 2002; Petersen et al., 2016). Evidently, myosin $\mathrm{X}$ is known to induce the formation of filopodia, an actin based membrane protrusion, which plays a critical role in cell migration and cell-cell interaction in various cell types (Berg \& Cheney, 2002; Kerber et al., 2009). Recently, studies have revealed that the unique cellular function of myosin $\mathrm{X}$ can be explained exclusively by the structural and functional properties at the molecular level. This review is based upon a recent progress in the regulation of myosin $\mathrm{X}$ and its function on actin cytoskeletal rearrangement to facilitate the formation of membrane protrusion, and maintain of structural integrity of membrane protrusive structures.

\section{STRUCTURE OF MYOSIN X}

Myosin X is composed of a conserved motor domain in its N- terminal region, a neck region consisting of three IQ motifs serving as light chain binding sites, a predicted coiled-coil domain and a unique tail domain, which consists of a PEST domain, three pleckstrin homology domains, a myosin tail homology 4 (MyTH4) domain and a band 4.1/ezrin/radixin/ moesin (FERM) domain (Berg et al., 2000) (Fig. 1A). The IQ motif has a consensus sequence (IQxxxRGxxxR) which binds to $\mathrm{Ca}^{2+}$ binding proteins (Cheney \& Mooseker, 1992; Rhoads \& Friedberg, 1997). Generally, the IQ motifs of conventional myosin (myosin II) bind specific light chains, i.e., regulatory light chain and essential light chain, while majority of the unconventional myosin uses calmodulin as its light chain associated with the IQ motifs (Wolenski, 1995). Recent studies have revealed that myosin 18A binds an ELC and a RLC (Guzik-Lendrum et al., 2013) and myosin 15A binds RLC and ELC (Bird et al., 2014) in its IQ domain. Previously, we demonstrated that human myosin VIIA can bind RLC at its IQ domains, although the affinity for RLC was lower than that of calmodulin (Sakai et al., 2015). It was reported that

(a) This is an open-access article distributed under the terms of the Creative Commons Attribution Non-Commercial License (http://creativecommons.org/licenses/by-nc/4.0) which permits unrestricted noncommercial use, distribution, and reproduction in any medium, provided the original work is properly cited.

Copyrights @ 2018 by Korean Society of Microscopy 
A

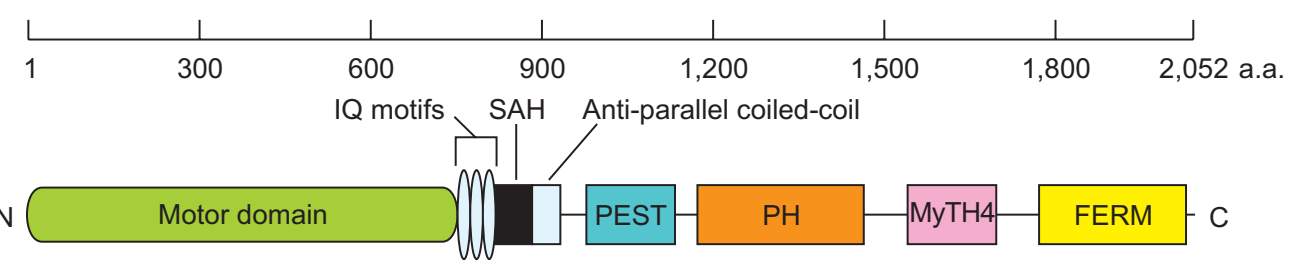

B

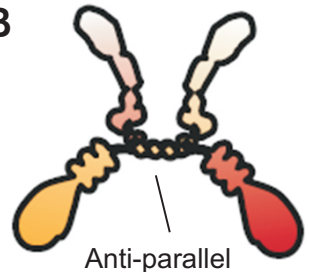

Fig. 1. Structure of myosin X. (A) Domain structure of myosin X. SAH, single alpha-helix; PEST, peptide sequence that is rich in proline, glutamic acid, serine, and threonine; MyTH4, myosin tail homology 4; FERM, F for 4.1 protein, E for ezrin, R for radixin and M for moesin. Amino acid number is shown on the top. (B) Schematic drawing of myosin X dimer with antiparallel coiled-coil structure. Two heavy chains are indicated by red and orange.

calmodulin-like protein can bind to the IQ domain of myosin $\mathrm{X}$ and it colocalizes with myosin $\mathrm{X}$ in MCF-7 breast cancer cell (Rogers \& Strehler, 2001). These results suggest that myo$\sin \mathrm{X}$ can associate with multiple light chains. It is plausible that the light chains associated with myosin $\mathrm{X}$ is dependent on the expression level of these $\mathrm{Ca}^{2+}$ binding proteins in each cell types, and identity of physiological light chain of myosin $\mathrm{X}$ is an unsolved question.

Because of the presence of a predicted coiled-coil domain, myosin $\mathrm{X}$ was originally thought to be a dimeric myosin (Berg et al., 2000). However, there have been reports illustrating the full length myosin X as being monomeric (Knight et al., 2005; Umeki et al., 2011), suggesting the coiled-coil association of myosin $\mathrm{X}$ not being strong enough to maintain a stable dimer formation. Proximal region of the predicted coiled-coil domain forms a stable single alpha-helix (SAH) (Knight et al., 2005) and it is this structure which may be functioning as an extension of a lever-arm contributing to a large step size of myosin X having only three IQ motifs (Fig. 1A). Another important feature of this domain is that the distal coiled-coil domain fragment forms an anti-parallel dimer based upon the structural analysis using nuclear magnetic resonance (NMR) spectroscopy (Lu et al., 2012) (Fig. 1B). In addition the antiparallel nature of the coiled-coil of myosin $\mathrm{X}$ is associated with a unique stepping of myosin X (Caporizzo et al., 2018; Ropars et al., 2016; Sato et al., 2017). Determination of the three-dimensional structure of MyTH4-FERM domain present in myosin X tail (Hirano et al., 2011; Wei et al., 2011), revealed an interaction of the two domains to form a supramodule with some key polar residues forming an interface between MyTH4 and FERM subdomains.

The tail domain being able to bind various proteins and signaling molecules is critical for determining the targets to exert its motor activity. Myosin X transports vasodilator-stimulated phosphoprotein (VASP), an actin uncapping protein, to filopodial tips thus facilitating actin elongation (He et al., 2017; Tokuo \& Ikebe, 2004). Integrin- $\beta$ was shown to co-localize with myosin $\mathrm{X}$ at the filopodial tips, and elimination of the MyTH4-FERM domain hampered the colocalization (Watanabe et al., 2010; Zhang et al., 2004). Originally, myosin X was proposed to move integrin $-\beta$ towards filopodial tips as a cargo molecule, but recent study suggestes that the apparent colocalization of myosin $X$ and integrin- $\beta$ at the filopodial tips is not due to the direct transportation of integrin- $\beta$ by myosin $\mathrm{X}$ (He et al., 2017). The tail domain is involved not only in binding various proteins but also in phospholipid binding through its pleckstrin homology $(\mathrm{PH})$ domains (Haslam et al., 1993; Lu et al., 2011; Musacchio et al., 1993; Umeki et al, 2011). Moreover, this $\mathrm{PH}$ domain plays a critical role in the regulation of myosin X molecules (Lu et al., 2011; Umeki et al., 2011) (see Regulation of the motor activity of myosin X).

\section{REGULATION OF THE MOTOR ACTIVITY OF MYOSIN X MOLECULE}

One of the most important concept in understanding the cellular function of myosin $\mathrm{X}$ is the regulation mechanism of myosin $\mathrm{X}$ at the molecular level. The regulation of the myosin motor activity is seen to be closely correlated with the conformational change in the myosin molecule. The motor activity of vertebrate smooth muscle and non-muscle myosin II is activated by the phosphorylation of the regulatory light chain associated with its neck domain, and the phosphorylation changes the conformation of myosin II from a folded inhibited conformation, wherein the two heads interacts with each other to stabilize the inhibited conformation, to an extended conformation (Ikebe, 2008; Sellers \& Knight, 2007; Tan et al., 1992; Trybus, 1991). Vertebrate myosin V forms a folded inhibited conformation, where the globular tail domain folds back to attach the motor head domain, and $\mathrm{Ca}^{2+}$ binding at the calmodulin light chain at the neck destabilizes the headtail interaction to release the inhibited conformation (Krementsov et al., 2004; Li et al., 2004, 2006, 2008; Wang et al., 2004).

Originally, actin-activated ATP hydrolase (ATPase) activity of full-length myosin $\mathrm{X}$ was recognized to be significantly lower than that of the tail-truncated myosin X (Umeki et al., 2011), suggesting that the tail domain may function as an intra-molecular inhibitor. Supporting this notion, the isolated tail domain was found to inhibit the ATPase activity of the tail-truncated myosin X (Umeki et al., 2011). Electron microscopic observation revealed that a full length myosin $\mathrm{X}$ is a 
monomer and forms a compact folded structure, in which the tail domain folds back towards the head-neck domain (Umeki et al., 2011). These findings indicate that the tail domain interacts with the head-neck domain to produce an inhibited conformation. However, the critical question is how the inhibition is reversed to activate myosin X. Unlike other myosins such as myosin V and myosin VIIa (Krementsov et al., 2004; Li et al., 2004; Sakai et al., 2015; Umeki et al., 2009; Wang et al., 2004), $\mathrm{Ca}^{2+}$ does not activate the myosin X's ATPase activity (Umeki et al., 2011). Since the interaction between the tail and the motor-neck domain is involved in the tail-dependent inhibition, it is plausible that the molecules binding at the tail domain of myosin $\mathrm{X}$ influence the stability of the inhibited conformation, thus activating the motor function of myosin $\mathrm{X}$. As described above, myosin $\mathrm{X}$ contains the $\mathrm{PH}$-domain between the PEST domain and the MyTH4 domain, and it was found that PtdIns $(3,4,5) \mathrm{P}_{3}$ can bind to this $\mathrm{PH}$ domain (Plantard et al., 2010; Umeki et al., 2011). A critical finding was that binding of PtdIns $(3,4,5) \mathrm{P}_{3}$ at the $\mathrm{PH}$ domain of myosin $\mathrm{X}$ activates the actin-activated ATPase activity of full-length myosin $\mathrm{X}$ to that of tail-truncated myosin $\mathrm{X}$, indicating that PtdIns $(3,4,5) \mathrm{P}_{3}$ binding to the $\mathrm{PH}$ domain interferes with the tail-head interaction, thus activating myosin $\mathrm{X}$ (Umeki et al., 2011). As described above, myosin $\mathrm{X}$ has a coiled-coil domain at the C-terminal side of the IQ domain, thus it was originally predicted that myosin $\mathrm{X}$ is a dimer. Importantly, $\operatorname{PtdIns}(3,4,5)$ $\mathrm{P}_{3}$ binding at the $\mathrm{PH}$ domain of myosin $\mathrm{X}$ tail induced the dimerization of myosin $\mathrm{X}$. Since PtdIns $(3,4,5) \mathrm{P}_{3}$ binding abolishes that tail-head interaction, the folded conformation of myosin $\mathrm{X}$ monomer is expected to be disrupted to form an extended conformation. It is thought that this exposes the coiled-coil domain that facilitates the coiled-coil formation to produce a myosin X dimer (Fig. 2).

\section{MYOSIN X AND FILOPODIA FORMATION}

One of the most important function of myosin $\mathrm{X}$ is the promotion of filopodia formation. Myosin X exhibits a striking localization at the tips of filopodia. (Berg \& Cheney, 2002; Berg et al., 2000; Bohil et al., 2006; Kerber \& Cheney, 2011; Tokuo \& Ikebe, 2004; Tokuo et al., 2007; Umeki et al., 2011; Watanabe et al., 2010) implying its movement on actin parallel bundles towards the filopodial tips. A key finding is that myosin $\mathrm{X}$ overexpression leads to a dramatic increase in the number and length of filopodia (Berg \& Cheney, 2002), while knockdown of the expression of endogenous myosin $\mathrm{X}$ by small interference RNA led to the loss of filopodia (Berg \& Cheney, 2002). These findings suggest that myosin X plays a critical role in filopodia formation.

Filopodia, finger-like cell surface projections composed of parallel bundles of actin filaments, plays a vital role in diverse cell motility processes including exploratory functions in cell migration, adhesion to the extracellular matrix (ECM), guidance towards chemo-attractants, and neuronal growth-cone path finding (Zhu et al., 2007), inferring the role of myosin X in the regulation of variety of cell motility activities.

\section{MECHANISM OF MYOSIN X INDUCED FILOPODIA FORMATION}

Several actin regulatory proteins such as cdc42, formin, VASP, fascin regulate the formation of filopodia by changing actin polymerization/depolymerization and actin bundling (Bear et al., 2000, 2002; Faix \& Rottner, 2006; Gupton \& Gertler, 2007; Svitkina \& Borisy, 1999; Svitkina et al., 2003; Welch \& Mullins, 2002). It was originally thought that myosin X-induced filopodia formation is due to the delivery of actin regulatory proteins to the cell peripheries by its motor activity, from where nascent filopodia are produced. A critical finding is that myosin $\mathrm{X}$ without cargo binding domain can initiate filopodia formation once it forms a dimer (Tokuo et al., 2007). Druginduced dimerization caused the tailless myosin $\mathrm{X}$ to induce filopodia (Tokuo et al., 2007), thus indicating the motor activity of the two heads of myosin $\mathrm{X}$ as essential and sufficient to initiate filopodia. However, produced filopodia is very short and unstable (Tokuo et al., 2007), and it is thought that the tail domain is important for producing long and stable filopodia.

Myosin X is evolved from the same ancestor of myosin VII (Petersen et al., 2016), both of which have MyTH4-FERM domain in their tail. While both myosins can localize at the filopodial tips, myosin X but not mammalian myosin VII

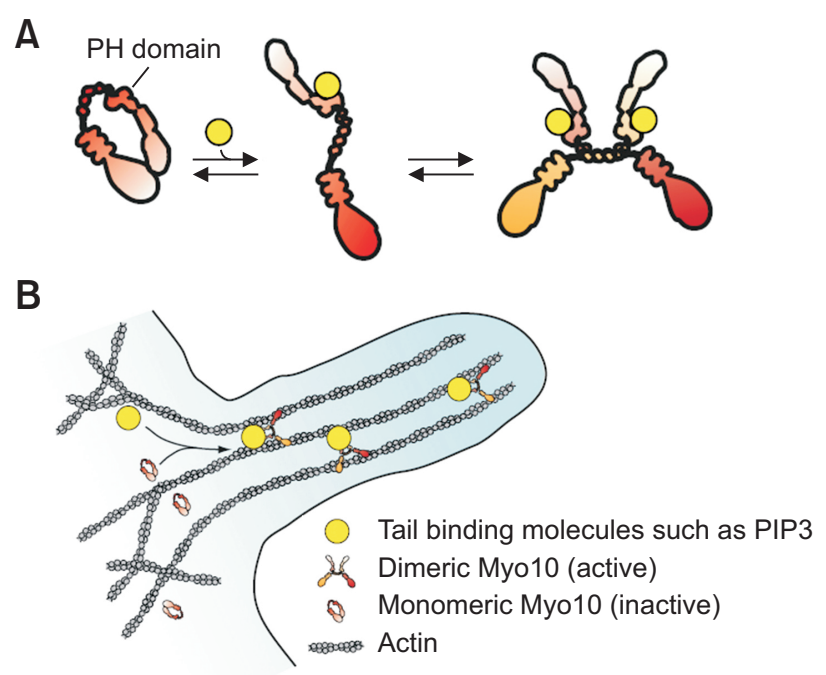

Fig. 2. Schematic drawing of myosin $X$ activation and movement in filopodia. (A) Model for the activation of myosin $\mathrm{X}$ by the tail binding cargo molecules. (B) Schematic model of myosin X movement in filopodia. $\mathrm{PH}$, pleckstrin homology. 
induces filopodia formation (Sakai et al., 2011; Umeki et al., 2011). Using NMR spectroscopy, Lu et al. (2012) found the predicted coiled-coil domain of myosin X forms stable antiparallel dimer, and proposed that the anti-parallel coiled-coil dimerization may be critical for the myosin $\mathrm{X}$ induced formation of filopodia.

On the other hand, it was found that full-length myosin $\mathrm{X}$ is monomeric, in which the tail domain folds back to the headneck domain (Umeki et al., 2011). Since PtdIns (3,4,5) $\mathrm{P}_{3}$ is enriched at the cell periphery, it is postulated that myosin $\mathrm{X}$ encounters PtdIns $(3,4,5) \mathrm{P}_{3}$ at cell peripheries, where myosin $\mathrm{X}$ produces an active dimer and utilizes its motor function to induce actin filament convergence to initiate filopodia formation (Umeki et al., 2011) (Fig. 2, 3).

The proposed scenario is that the two-headed myosin $\mathrm{X}$ can bind to two adjacent single actin filaments (Nagy et al., 2008; Ricca \& Rock, 2010; Sun et al., 2010; Tokuo et al., 2007). By acting like a zip fastener, myosin $\mathrm{X}$ helps to converge the local nucleated actin filaments to parallel actin filament bundles, thus forming the base of filopodia (Tokuo et al., 2007; Umeki et al., 2011) (Fig. 3). Supporting this notion, it was found that myosin $\mathrm{X}$ moves along the leading edge toward the nascent focal adhesion, where the myosin $\mathrm{X}$ binding partners are localized, and myosin $\mathrm{X}$ induces the formation of filopodia ( $\mathrm{He}$ et al., 2017; Tokuo et al., 2007; Umeki et al., 2011).

\section{MYOSIN X DEPENDENT STABLE FILOPODIA FORMATION AND MULTI-CYCLE EXTENSION OF FILOPODIA}

Since the filopodia induced by the tailless myosin $\mathrm{X}$ dimer was short and unstable (Tokuo et al., 2007), it was thought that transportation of the tail-binding cargo molecules plays a role in producing the stable and long filopodia. Supporting this view, actin-regulating proteins (e.g., VASP and integrin- $\beta$ ) are involved in regulating myosin $\mathrm{X}$-induced filopodia formation (Tokuo \& Ikebe, 2004; Zhang et al., 2004). Myosin X binds to and co-localize with VASP at filopodial tips (Tokuo \& Ikebe, 2004) (Fig. 3). The lack of VASP proteins in cortical neurons markedly inhibited filopodia formation, which could be res-
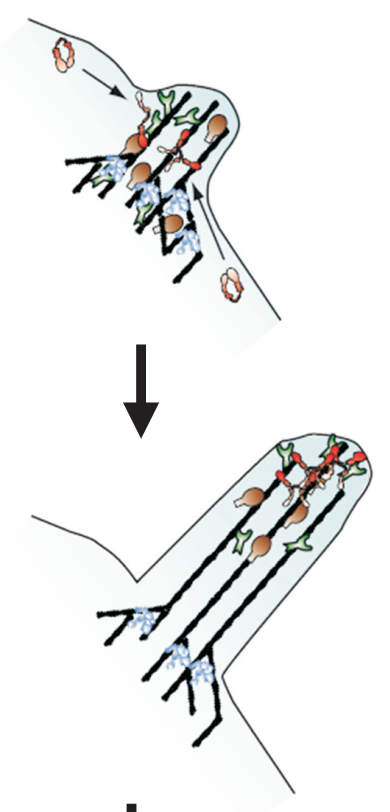

$\checkmark$
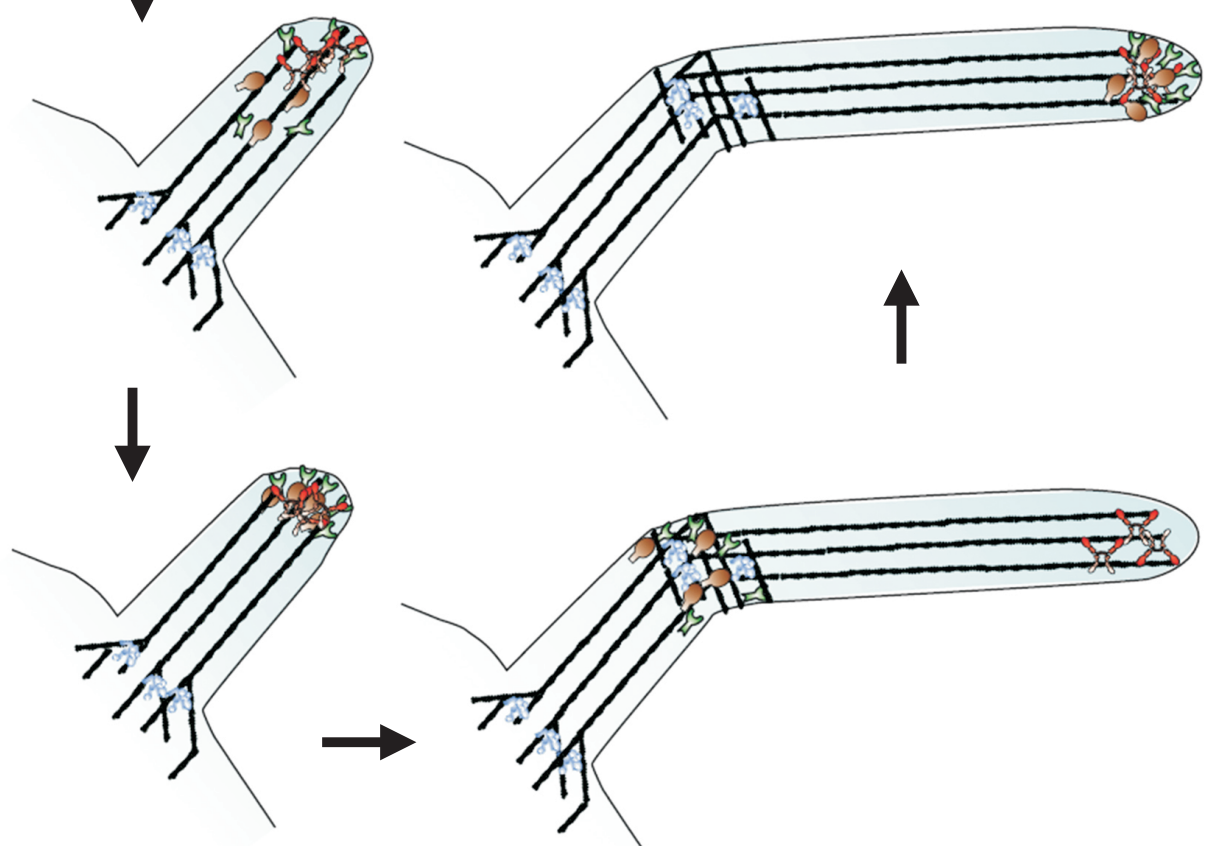

(8) Monomeric Myo10 (inactive)

\& Monomeric Myo10 (active)

\&f Dimeric Myo10 (active)

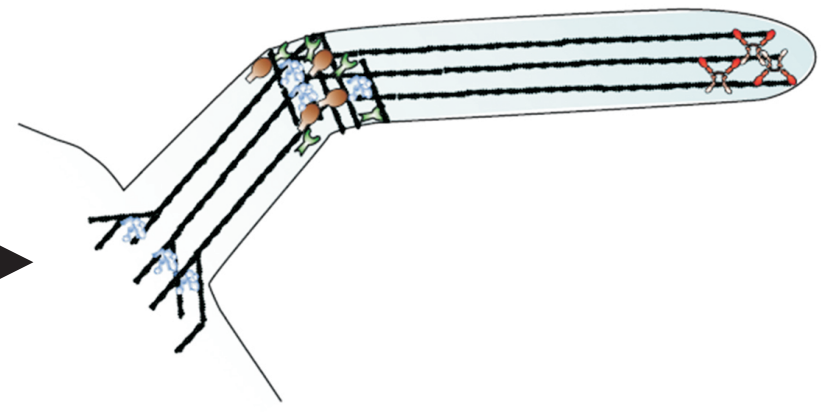

Fig. 3. Schematic model for myosin X induced multicycle filopodia elongation. 
cued by the expression of myosin X (Dent et al., 2007). These results suggest that myosin X and VASP concertedly promote filopodia formation and elongation.

It was also reported that myosin $\mathrm{X}$ binds to integrin- $\beta$, which is involved in filopodia formation (Zhang et al., 2004). The filopodia protrusion thus is performed by machinery composed of the interactions among actin-associated proteins mediated by myosin X (Tokuo \& Ikebe, 2004; Zhang et al., 2004). Importance of interaction between integrin- $\beta$ and myosin $\mathrm{X}$ interaction in filopodia elongation has been reported (Watanabe et al., 2010). It was found that myosin X induces multicycle extension of filopodia, and the elimination of the integrin- $\beta$ binding domain abolishes the multicycle extension, suggesting that the binding of integrin- $\beta$ to myosin $X$ is involved in the elongation of myosin $\mathrm{X}$ induced filopodia.

Quite recently, He et al. (2017) proposed that myosin X is recruited to the focal adhesions at the cell peripheries, from which nascent filopodia formation is induced based upon following observations (Fig. 3). 1. Intense nucleation event of actin was found along the cell's leading edge prior to filopodia formation; 2. Local nucleation of Arp2/3 was observed, from where subsequent filopodia formation took place, which suggests abundance of branched actin filaments before filopodia formation; 3 . Along with actin and Arp2/3, the focal adhesion proteins integrin- $\beta$ and vinculin were also accumulated at discrete points along the cell's leading edge prior to myosin $\mathrm{X}$ accumulation, from where nascent filopodia extended; 4 . The lateral movement of myosin $\mathrm{X}$ along the leading edge of nucleation sites, where gradual clustering of myosin $\mathrm{X}$ took place that was accompanied by the convergence of the local nucleated actin and Arp2/3 structure.

He et al. (2017) showed by live cell imaging that the second phase of myosin $\mathrm{X}$ induced nascent filopodia extension changes the direction with a wide-angle distribution. Interestingly, the long filopodia showed a bend at the middle of entire filopodia, where the focal adhesion proteins such as vinculin and integrin- $\beta$ as well as Arp $2 / 3$ are found. These findings suggest the second phase of filopodia extension initiates at the tip of filopodia produced by the first elongation, where both focal adhesion and the Arp2/3 induced polymerized actin structure are present.

A question is whether the accumulation of myosin $\mathrm{X}$ at the tips is sufficient to induce the second phase of filopodial extension. An interesting finding is obtained when a filopodial tip merged with the shaft of adjacent long filopodia. Myosin X accumulated at the tip of merged filopodia rapidly moved towards the tip of the long filopodia, however, the accumulated myosin X did not readily induce a second phase of extension from the tip of the newly produced filopodia. This suggests that myosin $\mathrm{X}$ accumulation at the filopodia tip is not sufficient to induce the second cycle of filopodia elongation. It was observed the gradual accumulation of integrin- $\beta$, vincu- lin and Arp $2 / 3$ at the myosin X-induced filopodia tips prior to the initiation of second cycle of filopodia extension (He et al., 2017). Conclusively, these findings raise the following scenario for multicycle extension of myosin X induced filopodia formation (Fig. 3).

Myosin $\mathrm{X}$ is recruited to the nascent focal adhesion at the cell's leading edge. Myosin X moves laterally along the leading edge, converges the actin structure and then produces the base of filopodia. Furthermore, myosin X moves on the parallel bundles of actin filaments in the newly produced filopodia and accumulates at the filopodial tip. Once myosin $\mathrm{X}$ is accumulated at the filopodial tip, integrin- $\beta$ diffuses along the filopodia and gathers at the tip via binding to myosin X. Arp2/3 is also recruited to the tip and facilitates actin nucleation. Myosin X again converges the actin structures to facilitate actin bundle formation and subsequently induces the second cycle of filopodia extension.

\section{MYOSIN X INDUCED FILOPODIA FORMATION AND PROCESSIVE MOVEMENT OF MYOSIN X WITH WIDE ANGLE DIRECTIONALITY}

It is likely that myosin X's unique activity of filopodia formation is correlated with the unique motor function of myosin $\mathrm{X}$ molecule. Myosin $\mathrm{X}$ is a high duty ratio motor (Homma \& Ikebe, 2005). Consistently, myosin X dimer with exogenous parallel forced dimer motifs can show processive movement (Bao et al., 2013; Nagy et al., 2008; Sun et al., 2010; Takagi et al., 2014). However, processivity of myosin dimer on various actin structures has been controversial. Nagy et al. (2008) showed the tail-truncated myosin $\mathrm{X}$ with exogenous forced dimerization motif at the $\mathrm{C}$-terminal end of the endogenous coiled-coil can processively move on fascin-actin bundles but is less processive on single actin filaments (Bao et al., 2013; Nagy et al., 2008) On the other hand, Sun et al. (2010) showed that the tail-truncated forced dimer of myosin $\mathrm{X}$ moves on single actin filaments as well as actin bundles without notable difference in processivity. The step size of myosin $\mathrm{X}$ is also controversial (Bao et al., 2013; Ricca \& Rock, 2010; Sun et al., 2010; Takagi et al., 2014), and the step size of the tail-truncated forced dimer of myosin $\mathrm{X}$ is reported to be $18 \mathrm{~nm}$ by one group (Ricca \& Rock, 2010), while the other group reported the step size to be 31 to $35 \mathrm{~nm}$ (Bao et al., 2013; Sun et al., 2010; Takagi et al., 2014). Apparent contradiction might be attribute to the position of the forced dimerization motifs after the innate coiled-coil of myosin $\mathrm{X}$ that is reported to form an antiparallel dimer (Lu et al., 2012; Ropars et al., 2016).

One of the best approaches to circumvent this problem and address the innate motor property of myosin $\mathrm{X}$ is the use of full-length myosin X. Recent studies have shown that the fulllength myosin $\mathrm{X}$ moves on synthetic actin bundles (Ropars et al., 2016) or filopodia (Sato et al., 2017) with wide range 
of step sizes. The results suggest that myosin $\mathrm{X}$ movement is flexible enough to land the heads on actin filaments in the bundled actin. Supporting this view, Sato et al. (2017) analyzed two-dimensional (2D) movement of the full-length myosin $\mathrm{X}$ and found that the myosin $\mathrm{X}$ shows $2 \mathrm{D}$ movement on filopodia with wide variety of step sizes towards X-, Y- and diagonal directions, which implies that the landing position of the myosin head can be the side of actin filaments. In another word, the lever-arm of full-length myosin $\mathrm{X}$ is flexible enough to step on various positions on actin filaments. This finding suggests that myosin $\mathrm{X}$ is a motor that can step to various angles in filopodia. This raises an idea that myosin X's flexible movement enables it to bridge different actin filaments in cell so that converge actin filaments to produce the base of filopodia.

\section{INTERACTION OF MYOSIN X WITH VARIOUS PARTNER MOLECULES AND POSSIBLE FUNCTION OF MYOSIN X IN DIVERSE CELL MOTILITY}

\section{Myosin X and DCC (Deleted Colorectal Cancer) in Neuronal Cells}

The axon path-finding is an important process during neural development and netrin and its receptors including DCC (deleted colorectal cancer) and neogenin play a role in this process (Chan et al., 1996; Keino-Masu et al., 1996; Kolodziej et al., 1996). Myosin X is reported to be involved in the transportation of netrin and its receptor DCC to the tips of neurites, where filopodial development takes place (Zhu et al., 2007). These findings suggest that myosin X plays a role in axon pathfinding during neuronal development.

Effect of DCC and neogenin on myosin X function is complex. DCC promotes myosin X movement on basal actin filaments in brain tumor cell line, while neogenin suppress the movement at the basal filaments but increases the movement at the dorsal side, and promotes dorsal filopodia formation (Liu et al., 2011). DCC binds to myosin X at the MyTH4FERM domain in the tail (Wei et al., 2011). Since the tail domain is involved in the regulation of the motor activity of myosin X (Umeki et al., 2011), these myosin X binding proteins may regulate the motor function of myosin $\mathrm{X}$ through the interaction with the tail domain, but further studies are required to clarify the regulation and function of myosin $\mathrm{X}$ in neuronal cell path finding process.

Myosin X depletion results in the defects in axon out growth (Yu et al., 2012). Myosin X expression induced multiple axonlike neurites, but interestingly this effect was motor activity independent (Yu et al., 2012). In the case of myosin X induced filopodia formation, the motor activity of myosin $\mathrm{X}$ is essential, and that the motor activity of myosin $\mathrm{X}$ facilitates actin filament convergence to produce the base of actin bundles for filopodia formation (Tokuo et al., 2007). It requires further study to clarify how myosin $\mathrm{X}$ without motor activity can induce axon-like neutrites.

\section{Myosin X and Microtubule}

Several reports have suggested that myosin X plays a role in mitotic spindle assembly and mitotic progression. ADD1 associates with mitotic spindles and is important for proper spindle assembly (Chan et al., 2014). Phosphorylation of ADD 1 by cyclin-dependent kinase 1 induces ADD1 to bind myosin X. Since mitotic defects by ADD1 depletion were rescued by wild type expression of ADD1 but not its mutant defective in myosin $\mathrm{X}$ binding, myosin $\mathrm{X}$ is likely to play a role in proper mitotic spindle assembly (Chan et al., 2014).

Myosin X was shown to interact with microtubules and influences spindle assembly during meiosis (Weber et al., 2004; Wuhr et al., 2008) and that myosin $\mathrm{X}$ is involved in proper delivery of chromosomes to daughter cells via its interaction with microtubules (Hirano et al., 2011) demonstrated the interaction of myosin X MyTH4-FERM domain with microtubules at the C-terminal acidic tail of tubulin (Hirano et al., 2011). Of interest is that this binding is competed with the binding to DCC and integrin- $\beta$ (Hirano et al., 2011). Myosin $\mathrm{X}$ may influence not only actin cytoskeletal organization but also microtubule based cytoskeletal structure.

\section{Myosin $\mathrm{X}$ and Cadherin}

Interaction of myosin $\mathrm{X}$ with cadherin has been suggested. Myosin X interacts with neuronal cadherin (N-cadherin) through the FERM domain and myosin X knock-down disrupted the distribution of $\mathrm{N}$-cadherin at cell surface (Lai et al., 2015). In vascular endothelial cells, myosin $X$ colocalized with VE-cadherin and co-immunoprecipitated with VE-cadherin complex (Almagro et al., 2010). Dominant negative myosin X disrupted the VE cadherin localization at cell edges, suggesting the involvement of myosin $\mathrm{X}$ in the transportation of $\mathrm{VE}$ cadherin. As the tail domain functions as an intramolecular inhibitor of myosin X (Umeki et al., 2011), it is plausible that these molecules influence the motor activity of myosin $\mathrm{X}$, presumably by disrupting the tail-head interaction of myosin $\mathrm{X}$ to release the tail-inhibition (Umeki et al., 2011). Further studies are required to clarify the effect of the interaction of cadherin with myosin $\mathrm{X}$ in the activation of the motor activity and function of myosin $\mathrm{X}$.

\section{Function of Myosin X in Cancer Development}

Recently, a number of studies have suggested the involvement of myosin $\mathrm{X}$ in various types of cancer progression (Arjonen et al., 2014; Cao et al., 2014; Courson \& Cheney, 2015). Involvement of myosin $\mathrm{X}$ in breast cancer cell invasion and dissemination was shown in multiple cancer cell lines and murine models of cancer metastasis (Arjonen et al., 2014). 
Deletion of the integrin- $\beta$ binding domain diminished the ability of the cancer cell invasion, providing its significance in translocation to filopodial tips. In clinical breast carcinomas, myosin X was predominantly expressed at the invasive edges and correlated with the presence of TP53 mutations and poor prognosis (Arjonen et al., 2014). It is conceivable that activation of myosin $\mathrm{X}$ is plays an important role in cancer progression, presumably due to the enhancement of metastasis. An actin based membrane protrusive structure, invadosome, plays a critical role in cellular invasion (Albiges-Rizo et al., 2009; Linder et al., 2011; Murphy \& Courtneidge, 2011; Saltel et al., 2011), and MMPs are thought to be released through invadosomes to degrade ECM proteins to facilitate cell invasion. Myosin X is suggested to be involved in this process.

Recent studies have revealed miRNAs to be involved in invasion and metastasis in several types of human cancer (Hu et al., 2008; Lin et al., 2010). miR-124 was found to be a tumorsuppressive microRNA in several cancers (Chen et al., 2015; Hunt et al., 2011; Peng et al., 2014), and decreased expression of miR-124 may be associated with tumorigenesis and metastasis by regulating its target gene (Wan et al., 2014). Recently, myosin $\mathrm{X}$ was identified as a direct and functional target of miR-124 (Sun et al., 2015). miR-340 expression suppresses tumor cell migration and invasion (Chen et al., 2016) whereas knockdown of miR-340 expression promotes breast cancer cell migration and invasion, and myosin $\mathrm{X}$ is found to be a direct miR-340 target gene. The mechanism of miRNA based regulation of myosin $\mathrm{X}$ function is interesting future target of myosin X study.

\section{PERSPECTIVE}

Myosin X has a unique antiparallel coiled-coil structure, allowing the formation of unique two-head orientation of myosin X that is likely to contribute to its unique 2D movement on actin bundles and myosin X's characteristic filopodia formation activity. However, the structural arrangement of myo$\sin \mathrm{X}$ and its associated proteins such as integrin- $\beta$, VASP and DCC along with actin filament bundles is not known, and future high resolution structural studies are required to uncover the molecular and structural basis of myosin X induced filopodia formation. It still remains a challenge to understand how myosin $\mathrm{X}$ becomes activated. One of the studies reported motor activity of myosin $\mathrm{X}$ being inhibited due to the interaction between the tail and the motor-neck domain of myosin $\mathrm{X}$ and PIP3 binding at the $\mathrm{PH}$ domain of the tail destabilizing the inhibited conformation, thus activating myosin $\mathrm{X}$ motor function. A number of myosin $\mathrm{X}$ binding proteins have been identified, and it is plausible that these binding partner molecules influence the interaction between the head-neck domain and the tail, thus activating the motor function of myosin X. The effect of the binding partner molecules on the motor function of myosin $\mathrm{X}$ needs to be clarified, and such studies would clarify the function of myosin $\mathrm{X}$ and its binding partner complex in diverse cellular function of myosin X. Another challenge is to clarify the role of myosin $\mathrm{X}$ in microtubule based motility. Actin and microtubule structures are influenced with each other (Even-Ram et al., 2007), and myosin $\mathrm{X}$ is shown to interact with microtubules and plays a role in mitotic spindle assembly, suggesting that myosin X's function on the reorganization of actin cytoskeletal structure might be involved in the microtubule structural network. Possible function of myosin $\mathrm{X}$ in the communication between actin and microtubule cytoskeletons in diverse cell motility is another research area of interest.

Since myosin X plays a role in actin cytoskeletal reorganization, it is expected that myosin X malfunction or over activation results in abnormal behavior of the cells.Role of myosin $\mathrm{X}$ in cancer progression is one of the most intriguing research areas, and a number of studies have suggested the involvement of myosin $\mathrm{X}$ in cancer development. It is reasonable to assume that myosin $\mathrm{X}$ alters the actin cytoskeletal structures, thus promoting cell migration and invasion that might be involved in the formation of actin protrusive structures such as invadosomes. However, the role of myosin X in the formation and activation of invadosomes including metalloproteinase secretion is poorly understood. Recent studies have suggested that myosin $\mathrm{X}$ is also involved in tunneling nanotube formation of neuronal cells (Gousset et al., 2013) and osteoclast precursors (Tasca et al., 2017), suggesting the role of myosin $\mathrm{X}$ in cell-cell communications. Future studies including structural analysis of actin protrusive structures with myosin $\mathrm{X}$ are required to uncover the role of myosin $\mathrm{X}$ in various biological processes and disease progression.

\section{CONFLICT OF INTEREST}

No potential conflict of interest relevant to this article was reported.

\section{ACKNOWLEDGMENTS}

This work is supported by NIH grants DC006103, AR048898, AR048526, HL073050 and HL111696. M.I. is a recipient of Texas Stars Plus award. 


\section{REFERENCES}

Albiges-Rizo C, Destaing O, Fourcade B, Planus E, and Block M R (2009) Actin machinery and mechanosensitivity in invadopodia, podosomes and focal adhesions. J. Cell Sci. 122, 3037-3049.

Almagro S, Durmort C, Chervin-Petinot A, Heyraud S, Dubois M, Lambert O, Maillefaud C, Hewat E, Schaal J P, Huber P, and Gulino-Debrac D (2010) The motor protein myosin-X transports VE-cadherin along filopodia to allow the formation of early endothelial cell-cell contacts. Mol. Cell Biol. 30, 1703-1717.

Arjonen A, Kaukonen R, Mattila E, Rouhi P, Hognas G, Sihto H, Miller B W, Morton J P, Bucher E, Taimen P, Virtakoivu R, Cao Y, Sansom O J, Joensuu H, and Ivaska J (2014) Mutant p53-associated myosin-X upregulation promotes breast cancer invasion and metastasis. J. Clin. Invest. 124, 1069-1082.

Bao J, Huck D, Gunther L K, Sellers J R, and Sakamoto T (2013) Actin structure-dependent stepping of myosin $5 a$ and 10 during processive movement. PLoS One 8, e74936.

Bear J E, Loureiro J J, Libova I, Fassler R, Wehland J, and Gertler F B (2000) Negative regulation of fibroblast motility by Ena/VASP proteins. Cell 101, 717-728.

Bear J E, Svitkina T M, Krause M, Schafer D A, Loureiro J J, Strasser G A, Maly I V, Chaga O Y, Cooper J A, Borisy G G, and Gertler F B (2002) Antagonism between Ena/VASP proteins and actin filament capping regulates fibroblast motility. Cell 109, 509-521.

Berg J S and Cheney R E (2002) Myosin-X is an unconventional myosin that undergoes intrafilopodial motility. Nat. Cell Biol. 4, 246-250.

Berg J S, Derfler B H, Pennisi C M, Corey D P, and Cheney R E (2000) Myosin-X, a novel myosin with pleckstrin homology domains, associates with regions of dynamic actin. J. Cell Sci. 113 (Pt 19), 3439-3451.

Bird J E, Takagi Y, Billington N, Strub M P, Sellers J R, and Friedman T B (2014) Chaperone-enhanced purification of unconventional myosin 15 , a molecular motor specialized for stereocilia protein trafficking. Proc. Natl. Acad. Sci. U. S. A. 111, 12390-12395.

Bohil A B, Robertson B W, and Cheney R E (2006) Myosin-X is a molecular motor that functions in filopodia formation. Proc. Natl. Acad. Sci. U. S. A. 103, 12411-12416.

Cao R, Chen J, Zhang X, Zhai Y, Qing X, Xing W, Zhang L, Malik Y S, Yu $H$, and Zhu $X$ (2014) Elevated expression of myosin $X$ in tumours contributes to breast cancer aggressiveness and metastasis. Br. J. Cancer 111, 539-550.

Caporizzo M A, Fishman C E, Sato O, Jamiolkowski R M, Ikebe M, and Goldman Y E (2018) The antiparallel dimerization of myosin X impairs bundle selectivity for processive motility. Biophys. J. 114, 14001410.

Chan P C, Hsu R Y, Liu C W, Lai C C, and Chen H C (2014) Adducin-1 is essential for mitotic spindle assembly through its interaction with myosin-X. J. Cell Biol. 204, 19-28.

Chan S S, Zheng H, Su M W, Wilk R, Killeen M T, Hedgecock E M, and Culotti J G (1996) UNC-40, a C. elegans homolog of DCC (Deleted in Colorectal Cancer), is required in motile cells responding to UNC-6 netrin cues. Cell 87, 187-195.

Chen C P, Sun Z L, Lu X, Wu W X, Guo W L, Lu J J, Han C, Huang J Q, and Fang $Y$ (2016) MiR-340 suppresses cell migration and invasion by targeting MYO10 in breast cancer. Oncol. Rep. 35, 709-716.

Chen Z, Liu S, Tian L, Wu M, Ai F, Tang W, Zhao L, Ding J, Zhang L, and Tang A (2015) miR-124 and miR-506 inhibit colorectal cancer pro- gression by targeting DNMT3B and DNMT1. Oncotarget 6, 3813938150.

Cheney R E and Mooseker M S (1992) Unconventional myosins. Curr. Opin. Cell Biol. 4, 27-35.

Courson D S and Cheney R E (2015) Myosin-X and disease. Exp. Cell Res. 334, 10-15.

Dent E W, Kwiatkowski A V, Mebane L M, Philippar U, Barzik M, Rubinson D A, Gupton S, Van Veen J E, Furman C, Zhang J, Alberts A S, Mori S, and Gertler F B (2007) Filopodia are required for cortical neurite initiation. Nat. Cell Biol. 9, 1347-1359.

Even-Ram S, Doyle A D, Conti M A, Matsumoto K, Adelstein R S, and Yamada K M (2007) Myosin IIA regulates cell motility and actomyosinmicrotubule crosstalk. Nat. Cell Biol. 9, 299-309.

Faix J and Rottner K (2006) The making of filopodia. Curr. Opin. Cell Biol. 18, $18-25$.

Gousset K, Marzo L, Commere P H, and Zurzolo C (2013) Myo10 is a key regulator of TNT formation in neuronal cells. J. Cell Sci. 126, 44244435.

Gupton S L and Gertler F B (2007) Filopodia: the fingers that do the walking. Sci. STKE 2007, re5.

Guzik-Lendrum S, Heissler S M, Billington N, Takagi Y, Yang Y, Knight P J, Homsher E, and Sellers J R (2013) Mammalian myosin-18A, a highly divergent myosin. J. Biol. Chem. 288, 9532-9548.

Haslam R J, Koide H B, and Hemmings B A (1993) Pleckstrin domain homology. Nature 363, 309-310.

He K, Sakai T, Tsukasaki Y, Watanabe T M, and Ikebe M (2017) Myosin $X$ is recruited to nascent focal adhesions at the leading edge and induces multi-cycle filopodial elongation. Sci. Rep. 7, 13685.

Hirano Y, Hatano T, Takahashi A, Toriyama M, Inagaki N, and Hakoshima $T$ (2011) Structural basis of cargo recognition by the myosin-X MyTH4-FERM domain. EMBO J. 30, 2734-2747.

Homma K and Ikebe M (2005) Myosin X is a high duty ratio motor. J. Biol. Chem. 280, 29381-29391.

Hu Z, Chen J, Tian T, Zhou X, Gu H, Xu L, Zeng Y, Miao R, Jin G, Ma H, Chen $Y$, and Shen $H$ (2008) Genetic variants of miRNA sequences and non-small cell lung cancer survival. J. Clin. Invest. 118, 26002608.

Hunt S, Jones A V, Hinsley E E, Whawell S A, and Lambert D W (2011) MicroRNA-124 suppresses oral squamous cell carcinoma motility by targeting ITGB1. FEBS Lett. 585, 187-192.

Ikebe M (2008) Regulation of the function of mammalian myosin and its conformational change. Biochem. Biophys. Res. Commun. 369, 157164.

Keino-Masu K, Masu M, Hinck L, Leonardo E D, Chan S S, Culotti J G, and Tessier-Lavigne M (1996) Deleted in Colorectal Cancer (DCC) encodes a netrin receptor. Cell 87, 175-185.

Kerber M L and Cheney R E (2011) Myosin-X: a MyTH-FERM myosin at the tips of filopodia. J. Cell Sci. 124, 3733-3741.

Kerber M L, Jacobs D T, Campagnola L, Dunn B D, Yin T, Sousa A D, Quintero O A, and Cheney R E (2009) A novel form of motility in filopodia revealed by imaging myosin- $X$ at the single-molecule level. Curr. Biol. 19, 967-973.

Knight P J, Thirumurugan K, Xu Y, Wang F, Kalverda A P, Stafford W F 3rd, 
Sellers J R, and Peckham M (2005) The predicted coiled-coil domain of myosin 10 forms a novel elongated domain that lengthens the head. J. Biol. Chem. 280, 34702-34708.

Kolodziej P A, Timpe L C, Mitchell K J, Fried S R, Goodman C S, Jan L Y, and Jan Y N (1996) frazzled encodes a Drosophila member of the DCC immunoglobulin subfamily and is required for CNS and motor axon guidance. Cell 87, 197-204.

Krementsov D N, Krementsova E B, and Trybus K M (2004) Myosin V: regulation by calcium, calmodulin, and the tail domain. J. Cell Biol. 164, 877-886.

Lai M, Guo Y, Ma J, Yu H, Zhao D, Fan W, Ju X, Sheikh M A, Malik Y S, Xiong W, Guo W, and Zhu X (2015) Myosin X regulates neuronal radial migration through interacting with $\mathrm{N}$-cadherin. Front. Cell $\mathrm{Neu}$ rosci. 9, 326.

Li X D, Jung H S, Mabuchi K, Craig R, and Ikebe M (2006) The globular tail domain of myosin $\mathrm{Va}$ functions as an inhibitor of the myosin Va motor. J. Biol. Chem. 281, 21789-21798.

Li X D, Jung H S, Wang Q, Ikebe R, Craig R, and Ikebe M (2008) The globular tail domain puts on the brake to stop the ATPase cycle of myosin Va. Proc. Natl. Acad. Sci. U. S. A. 105, 1140-1145.

Li X D, Mabuchi K, Ikebe R, and Ikebe M (2004) Ca2+-induced activation of ATPase activity of myosin $\mathrm{Va}$ is accompanied with a large conformational change. Biochem. Biophys. Res. Commun. 315, 538-545.

Lin S C, Liu C J, Lin J A, Chiang W F, Hung P S, and Chang K W (2010) miR-24 up-regulation in oral carcinoma: positive association from clinical and in vitro analysis. Oral. Oncol. 46, 204-208.

Linder S, Wiesner C, and Himmel M (2011) Degrading devices: invadosomes in proteolytic cell invasion. Annu. Rev. Cell Dev. Biol. 27, 185-211.

Liu Y, Hsin J, Kim H, Selvin P R, and Schulten K (2011) Extension of a three-helix bundle domain of myosin $\mathrm{VI}$ and key role of calmodulins. Biophys. J. 100, 2964-2973.

Lu Q, Ye F, Wei Z, Wen Z, and Zhang M (2012) Antiparallel coiled-coilmediated dimerization of myosin X. Proc. Natl. Acad. Sci. U. S. A. 109, 17388-17393.

Lu Q, Yu J, Yan J, Wei Z, and Zhang M (2011) Structural basis of the myo$\sin \mathrm{X} \mathrm{PH} 1(\mathrm{~N})-\mathrm{PH} 2-\mathrm{PH} 1(\mathrm{C})$ tandem as a specific and acute cellular $\mathrm{PI}(3,4,5) \mathrm{P}(3)$ sensor. Mol. Biol. Cell 22, 4268-4278.

Murphy D A and Courtneidge S A (2011) The 'ins' and 'outs' of podosomes and invadopodia: characteristics, formation and function. Nat. Rev. Mol. Cell Biol. 12, 413-426.

Musacchio A, Gibson T, Rice P, Thompson J, and Saraste M (1993) The $\mathrm{PH}$ domain: a common piece in the structural patchwork of signalling proteins. Trends Biochem. Sci. 18, 343-348.

Nagy S, Ricca B L, Norstrom M F, Courson D S, Brawley C M, Smithback P A, and Rock R S (2008) A myosin motor that selects bundled actin for motility. Proc. Natl. Acad. Sci. U. S. A. 105, 9616-9620.

Peng X H, Huang H R, Lu J, Liu X, Zhao F P, Zhang B, Lin S X, Wang L, Chen H H, XU X, Wang F, and Li X P (2014) MiR-124 suppresses tumor growth and metastasis by targeting Foxq1 in nasopharyngeal carcinoma. Mol. Cancer 13, 186.

Petersen K J, Goodson H V, Arthur A L, Luxton G W, Houdusse A, and Titus M A (2016) MyTH4-FERM myosins have an ancient and conserved role in filopod formation. Proc. Natl. Acad. Sci. U. S. A. 113, E8059E8068.

Plantard L, Arjonen A, Lock J G, Nurani G, Ivaska J, and Stromblad S (2010) Ptdlns $(3,4,5) P(3)$ is a regulator of myosin-X localization and filopodia formation. J. Cell Sci. 123, 3525-3534.

Rhoads A R and Friedberg F (1997) Sequence motifs for calmodulin recognition. FASEB J. 11, 331-340.

Ricca B L and Rock R S (2010) The stepping pattern of myosin X is adapted for processive motility on bundled actin. Biophys. J. 99, 18181826.

Rogers M S and Strehler E E (2001) The tumor-sensitive calmodulin-like protein is a specific light chain of human unconventional myosin X. J. Biol. Chem. 276, 12182-12189.

Ropars V, Yang Z, Isabet T, Blanc F, Zhou K, Lin T, Liu X, Hissier P, Samazan F, Amigues B, Yang E D, Park H, Pylypenko O, Cecchini M, Sinde$\operatorname{lar}$ C V, Sweeney H L, and Houdusse A (2016) The myosin X motor is optimized for movement on actin bundles. Nat. Commun. 7, 12456.

Sakai T, Jung H S, Sato O, Yamada M D, You D J, Ikebe R, and Ikebe M (2015) Structure and regulation of the movement of human myosin VIIA. J. Biol. Chem. 290, 17587-17598.

Sakai T, Umeki N, Ikebe R, and Ikebe M (2011) Cargo binding activates myosin VIIA motor function in cells. Proc. Natl. Acad. Sci. U. S. A. 108, 7028-7033.

Saltel F, Daubon T, Juin A, Ganuza I E, Veillat V, and Genot E (2011) Invadosomes: intriguing structures with promise. Eur. J. Cell Biol. 90, 100-107.

Sato O, Jung H S, Komatsu S, Tsukasaki Y, Watanabe T M, Homma K, and Ikebe M (2017) Activated full-length myosin-X moves processively on filopodia with large steps toward diverse two-dimensional directions. Sci. Rep. 7, 44237.

Sellers J R and Knight P J (2007) Folding and regulation in myosins II and V. J. Muscle Res. Cell Motil. 28, 363-370.

Sun Y, Ai X, Shen S, and Lu S (2015) NF-kappaB-mediated miR-124 suppresses metastasis of non-small-cell lung cancer by targeting MY010. Oncotarget 6, 8244-8254.

Sun Y, Sato O, Ruhnow F, Arsenault M E, Ikebe M, and Goldman YE (2010) Single-molecule stepping and structural dynamics of myosin X. Nat. Struct. Mol. Biol. 17, 485-491.

Svitkina T M and Borisy G G (1999) Arp2/3 complex and actin depolymerizing factor/cofilin in dendritic organization and treadmilling of actin filament array in lamellipodia. J. Cell Biol. 145, 1009-1026.

Svitkina T M, Bulanova E A, Chaga O Y, Vignjevic D M, Kojima S, Vasiliev J M, and Borisy G G (2003) Mechanism of filopodia initiation by reorganization of a dendritic network. J. Cell Biol. 160, 409-421.

Takagi Y, Farrow R E, Billington N, Nagy A, Batters C, Yang Y, Sellers J R, and Molloy J E (2014) Myosin-10 produces its power-stroke in two phases and moves processively along a single actin filament under low load. Proc. Natl. Acad. Sci. U. S. A. 111, E1833-1842.

Tan J L, Ravid S, and Spudich J A (1992) Control of nonmuscle myosins by phosphorylation. Annu. Rev. Biochem. 61, 721-759.

Tasca A, Astleford K, Lederman A, Jensen E D, Lee B S, Gopalakrishnan $\mathrm{R}$, and Mansky K C (2017) Regulation of osteoclast differentiation by myosin X. Sci. Rep. 7, 7603.

Tokuo $\mathrm{H}$ and Ikebe M (2004) Myosin X transports Mena/VASP to the tip of filopodia. Biochem. Biophys. Res. Commun. 319, 214-220.

Tokuo H, Mabuchi K, and Ikebe M (2007) The motor activity of myosin$\mathrm{X}$ promotes actin fiber convergence at the cell periphery to initiate filopodia formation. J. Cell Biol. 179, 229-238.

Trybus K M (1991) Regulation of smooth muscle myosin. Cell Motil. Cytoskeleton 18, 81-85. 
Umeki N, Jung H S, Sakai T, Sato O, Ikebe R, and Ikebe M (2011) Phospholipid-dependent regulation of the motor activity of myosin X. Nat. Struct. Mol. Biol. 18, 783-788.

Umeki N, Jung H S, Watanabe S, Sakai T, Li X D, Ikebe R, Craig R, and Ikebe $M$ (2009) The tail binds to the head-neck domain, inhibiting ATPase activity of myosin VIIA. Proc. Natl. Acad. Sci. U. S. A. 106, 8483-8488.

Wan H Y, Li Q Q, Zhang Y, Tian W, Li Y N, Liu M, Li X, and Tang H (2014) MiR-124 represses vasculogenic mimicry and cell motility by targeting amotL1 in cervical cancer cells. Cancer Lett. 355, 148-158.

Wang F, Thirumurugan K, Stafford W F, Hammer J A 3rd, Knight P J, and Sellers J R (2004) Regulated conformation of myosin V. J. Biol. Chem. 279, 2333-2336.

Watanabe T M, Tokuo H, Gonda K, Higuchi H, and Ikebe M (2010) Myosin- $X$ induces filopodia by multiple elongation mechanism. J. Biol. Chem. 285, 19605-19614.

Weber K L, Sokac A M, Berg J S, Cheney R E, and Bement W M (2004) $A$ microtubule-binding myosin required for nuclear anchoring and spindle assembly. Nature 431, 325-329.
Wei Z, Yan J, Lu Q, Pan L, and Zhang M (2011) Cargo recognition mechanism of myosin $X$ revealed by the structure of its tail MyTH4-FERM tandem in complex with the DCC P3 domain. Proc. Natl. Acad. Sci. U. S. A. 108, 3572-3577.

Welch M D and Mullins R D (2002) Cellular control of actin nucleation. Annu. Rev. Cell Dev. Biol. 18, 247-288.

Wolenski J S (1995) Regulation of calmodulin-binding myosins. Trends Cell Biol. 5, 310-316.

Wuhr M, Mitchison T J, and Field C M (2008) Mitosis: new roles for myo$\sin -X$ and actin at the spindle. Curr. Biol. 18, R912-R914.

Yu H, Wang N, Ju X, Yang Y, Sun D, Lai M, Cui L, Sheikh M A, Zhang J, Wang X, and Zhu X (2012) Ptdlns (3,4,5) P3 recruitment of Myo10 is essential for axon development. PLoS One 7, e36988.

Zhang H, Berg J S, Li Z, Wang Y, Lang P, Sousa A D, Bhaskar A, Cheney $\mathrm{R} E$, and Stromblad S (2004) Myosin-X provides a motor-based link between integrins and the cytoskeleton. Nat. Cell Biol. 6, 523-531.

Zhu X J, Wang C Z, Dai P G, Xie Y, Song N N, Liu Y, Du Q S, Mei L, Ding Y Q, and Xiong W C (2007) Myosin X regulates netrin receptors and functions in axonal path-finding. Nat. Cell Biol. 9, 184-192. 